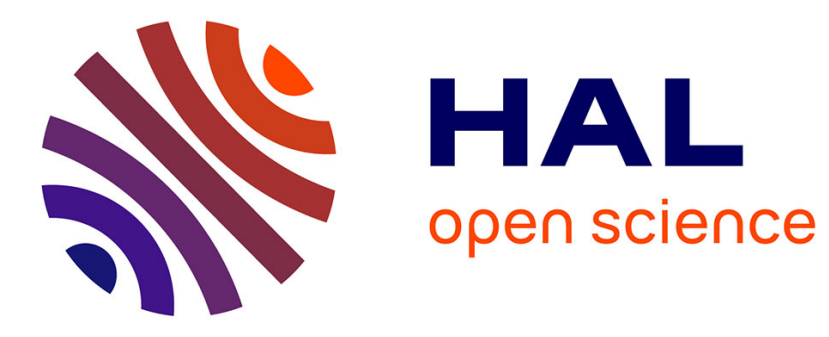

\title{
Combustion in micro-channels with a controlled temperature gradient
}

Annalisa Di Stazio, Christian Chauveau, Guillaume Dayma, Philippe Dagaut

\section{To cite this version:}

Annalisa Di Stazio, Christian Chauveau, Guillaume Dayma, Philippe Dagaut. Combustion in microchannels with a controlled temperature gradient. Experimental Thermal and Fluid Science, 2016, 73, pp.79 - 86. 10.1016/j.expthermflusci.2015.09.020 . hal-01858439

\section{HAL Id: hal-01858439 \\ https://hal.science/hal-01858439}

Submitted on 11 Oct 2021

HAL is a multi-disciplinary open access archive for the deposit and dissemination of scientific research documents, whether they are published or not. The documents may come from teaching and research institutions in France or abroad, or from public or private research centers.
L'archive ouverte pluridisciplinaire HAL, est destinée au dépôt et à la diffusion de documents scientifiques de niveau recherche, publiés ou non, émanant des établissements d'enseignement et de recherche français ou étrangers, des laboratoires publics ou privés. 


\title{
Combustion in micro-channels with a controlled temperature gradient
}

\author{
Annalisa Di Stazio ${ }^{\mathrm{a}, 1}$, Christian Chauveau ${ }^{\mathrm{a}}$, Guillaume Dayma ${ }^{\mathrm{a}, \mathrm{b}}$ and Philippe Dagaut \\ ${ }^{\mathrm{a}}$ CNRS - INSIS, $1 C$ av. de la Recherche Scientifique, 45071 Orléans cedex 2, France \\ ${ }^{\mathrm{b}}$ Université d'Orléans, Collegium Sciences et Techniques, 1 rue de Chartres, 45067 Orléans cedex 2, France
}

\begin{abstract}
In recent years many studies were undertaken in the field of micro-combustion, experimentally and numerically. In the present work, a new experimental device was developed. It consists of a micro tubular channel with an external heating provided by three hydrogen/oxygen flames positioned at the upstream side of the tube. This system ensures a uniform heating inside the channel. As described in previous studies, three distinct flame behaviors were observed: stable flames at high flow velocity, flames with repetitive extinction and ignition (FREI) in the middle flow range, and weak flames, at low flow velocity. This experimental study on the combustion of methane/air mixtures in a microchannel was undertaken to provide detailed information on flame behavior over a wide range of equivalence ratios (0.5-1.5) and flow velocities. Finally, a detailed analysis on the flame instabilities was performed. The results show a good agreement with several numerical results, and the study on FREI frequencies reveals a particular trend of instability with the change of the experimental conditions.
\end{abstract}

Keywords: Micro combustion, Micro combustor, Premixed combustion, Transient flame behaviors, Wall temperature

\section{Introduction}

Nowadays the growing need for low fuel consumption systems makes very attractive the development and the application of MicroElectroMechanical (MEMS) devices, which may produce more energy than the modern batteries by using hydrocarbon fuels $[1,2]$. This concept is coupled with that of "excess-enthalpy" combustion [3], which led to the design of a new device, called the Swiss Roll combustors [4] consisting of a micro reactor where the reactants are preheated by burned gas, with the combustion zone at the center of a pair of spiral channels. Recently channels with an inner diameter lower than the quenching diameter have been used for this burner [5,6], and the combustion stabilization in such devices is a far from trivial problem [7, 8]. In order to deepen and widen knowledge on micro-scale combustion, many studies have been performed $[9,10]$. With the reduction of the combustor's size, the difficulty to sustain a stable combustion increases, due to the larger surface to volume ratio. The effects of quenching, thermal and radical, both increase. However, with the continuous heating of the solid phase it is possible to sustain combustion in a tube having an internal diameter smaller than the ordinary quenching diameter and in lean conditions. Nevertheless, the management of the combustor flow and thermal conditions is required to reduce the wall effects [11]; the miniaturization enhances the heat losses [12] and, as shown in the previous studies, all the combustor design parameters influence the flame stabilization [13]. As observed by Popp and Baum [14], the wall heat flux increases with increasing wall

\footnotetext{
${ }^{1}$ Corresponding author at: CNRS ICARE, 1C, Avenue de la Recherche Scientifique, 45071 Orléans Cedex 2, France. Tel.: +33 (0) 238257943

E-mail address: annalisa.distazio@cnrs-orleans.fr (A. Di Stazio).
} 
temperature and the interaction between the flame and the wall is very fast: the higher the wall temperature is, the higher is the fuel consumption and the behavior of the reactive mixture changes, with an increase in concentration of $\mathrm{H}$ and $\mathrm{OH}$ species. High temperatures enhance the Soret effect, particularly for light species, resulting in a reduction of burning velocity $[15,16]$. As described by Maruta et al. [17], three distinct flame behaviors can be observed in narrow channels: bright and stable flames for high flow velocity, flames with repetitive extinction and ignition (FREI) in the intermediate flow rate range and weak flames at low flow velocity. The flame luminosity decreases with the reduction of the flow rate. The flame is stabilized in a certain position where balance between the flame temperature, wall heat losses and flow rate occurs.

The objective of this work is to provide detailed information on methane/air mixture flame behavior's in narrow channels. To this end, experiments at different conditions (flow velocity and equivalence ratio) were performed and instabilities analysis was conducted.

\section{Experimental set-up}

The experimental setup was designed to investigate the combustion in narrow channels with a premixed methane/air blend at atmospheric pressure. The micro reactor used here consists of a cylindrical quartz tube, inside which the gaseous mixture flows. This tube is heated from outside thanks to three blowtorches around the tube, separated from each other by $120^{\circ}$. This system ensures a stationary, homogeneous and Gaussian temperature profile starting from ambient temperature at the upstream side (gas inlet) to a maximum of $1600 \mathrm{~K}$ at downstream (gas outlet). This temperature slope allows the flame to auto-ignite, overcoming quenching issues. The three external heat sources are fed by a hydrogen/oxygen mixture. The heating flames are then free of $\mathrm{CH}^{*}$ species, which allows a better visualization of $\mathrm{CH}^{*}$ chemiluminescence from the flame studied inside the microchannel.

The methane/air mixture is premixed in a small tank and six thermal mass flowmeters Brooks GF40 (error less than 1\%) are used to feed the reactor. Each gas line $\left(\mathrm{CH}_{4}, \mathrm{O}_{2}, \mathrm{~N}_{2}\right)$ has 2 flowmeters with overlapping flow rate ranges, allowing a good exploration of all flame regimes.

The temperature distribution along the outer side of the tube is measured by a FLIR A655sc thermal camera with a $640 \times 480$ pixels matrix, with a measurement uncertainty of $\pm 3 \%$. The operating range is selected between 300 and $2000^{\circ} \mathrm{C}$. The temperature measurements are taken in real time at a frequency of $10 \mathrm{~Hz}$, which ensures a continuous recording of the temperature imposed to the micro reactor. An emissivity correction is carried out because in the operating spectral range of the camera $(7.5-14 \mu \mathrm{m})$, fused silica emissivity varies with temperature, as shown by Sova et al. [18].

A Princeton Instrument spectroscopy EMCCD camera (ProEM 1600), equipped with a $105-\mathrm{mm}$ Nikkor lens (f/2.8D), is used to detect the $\mathrm{CH}^{*}$ signal at $430 \mathrm{~nm}$. The CCD camera operates in a $1600 \times 200$ pixels matrix with a 16-bit output digitization. A band-pass filter (20BPF10-430) is used to observe the flame chemiluminescence through the quartz tube. In order to increase sensitivity and frame rate, binning operation and adapted exposure time are performed. The spatial resolution is 62 pixels $/ \mathrm{mm}$. For instable flames the maximum recording frequency of $4260 \mathrm{~Hz}$ is used.

A schematic representation of the experimental apparatus is showed in Fig. 1. The temperature profile along the tube is displayed in Fig. 2. The origin of the horizontal axis is set at the maximum of the temperature profile. 


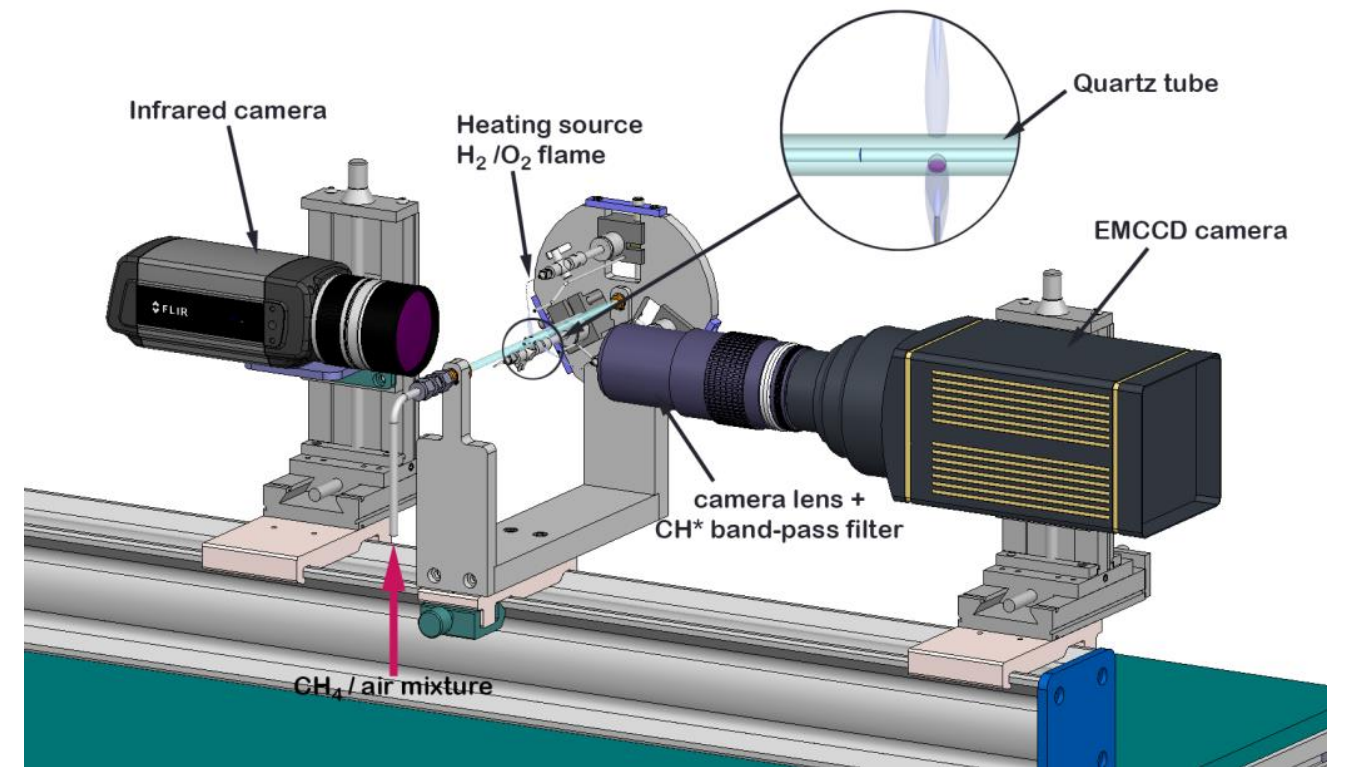

Fig. 1. The experimental set-up

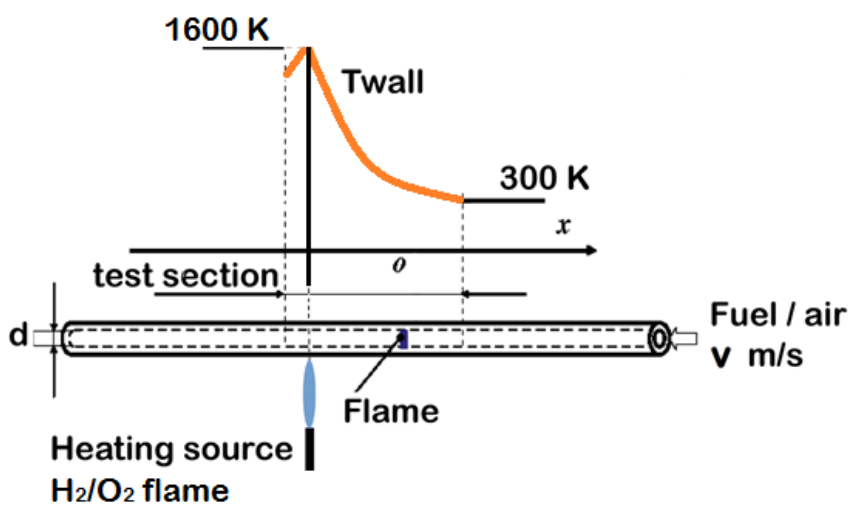

Fig. 2. Temperature profile along the tube.

Using this set-up, experiments were conducted over a range of flow rates from $0.03 \mathrm{~m} / \mathrm{s}$ to $1 \mathrm{~m} / \mathrm{s}$ in a $2.15 \mathrm{~mm}$ inner diameter tube and compared to those obtained in previous studies. Then experiments were performed in a $1.85 \mathrm{~mm}$ inner diameter tube over a range of equivalence ratios from 0.5 to 1.5 . Finally, to further examine the unstable regime, a study on FREI frequencies was carried out and the results are discussed.

\section{Results}

\subsection{Flame visualization}

After auto-ignition in the side downstream, the flame propagates upstream and finally stabilizes at a stable position in the temperature gradient where balance between the flame propagation velocity and the fresh gases flow rate is obtained. As observed in previous experiments by Maruta et al. [17], we also detected three dynamic flame behaviors depending on the inlet velocity: stable flames, Flames with Repetitive Extinction and Ignition (FREI) and weak flames.

Stable flames, set at a given position in the temperature gradient, show curvature that depends on the flow rate, as shown in Fig. 3. When the fresh gas flow rate is increased the flame moves towards the maximum of the imposed temperature profile. Due to increased heat losses, the flame temperature and flame speed become lower [19] and the shape of flame is driven by the incoming fresh gases velocity profile, as described in [20]. 

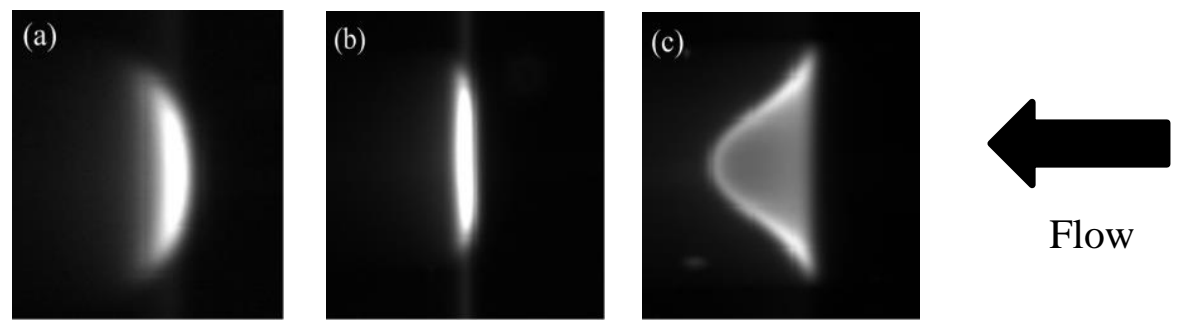

Flow

Fig. 3. Images of stable flames for stoichiometric $\mathrm{CH}_{4} /$ air mixtures in a $2.15 \mathrm{~mm}$ inner diameter tube. Flow rates: (a) $0.37 \mathrm{~m} / \mathrm{s}$, (b) $0.5 \mathrm{~m} / \mathrm{s}$, (c) $1 \mathrm{~m} / \mathrm{s}$.

Unstable flames, named FREI (flames with repetitive extinction and ignition) are present in the middle range of the inlet velocities $(0.05$ to $0.35 \mathrm{~m} / \mathrm{s})$. Ignition occurs downstream while extinction is observed upstream. The propagation is very fast and the extinction and ignition positions change as a function of the fresh gases flow rate.

We have also observed unstable oscillating flames, in the transition between stable flames and FREI regime. The flame ignites downstream, propagates upstream and oscillates before extinction. This phenomenon, reported previously by Tsuboi et al. [21] and called 'oscillating FREI', is highlighted on Figs. 4 and 5. This regime has been simulated numerically by Minaev et al. [22] using a 1D thermo-diffusive model and by Jackson et al. [23] using a fixed Poiseuille flow-field.
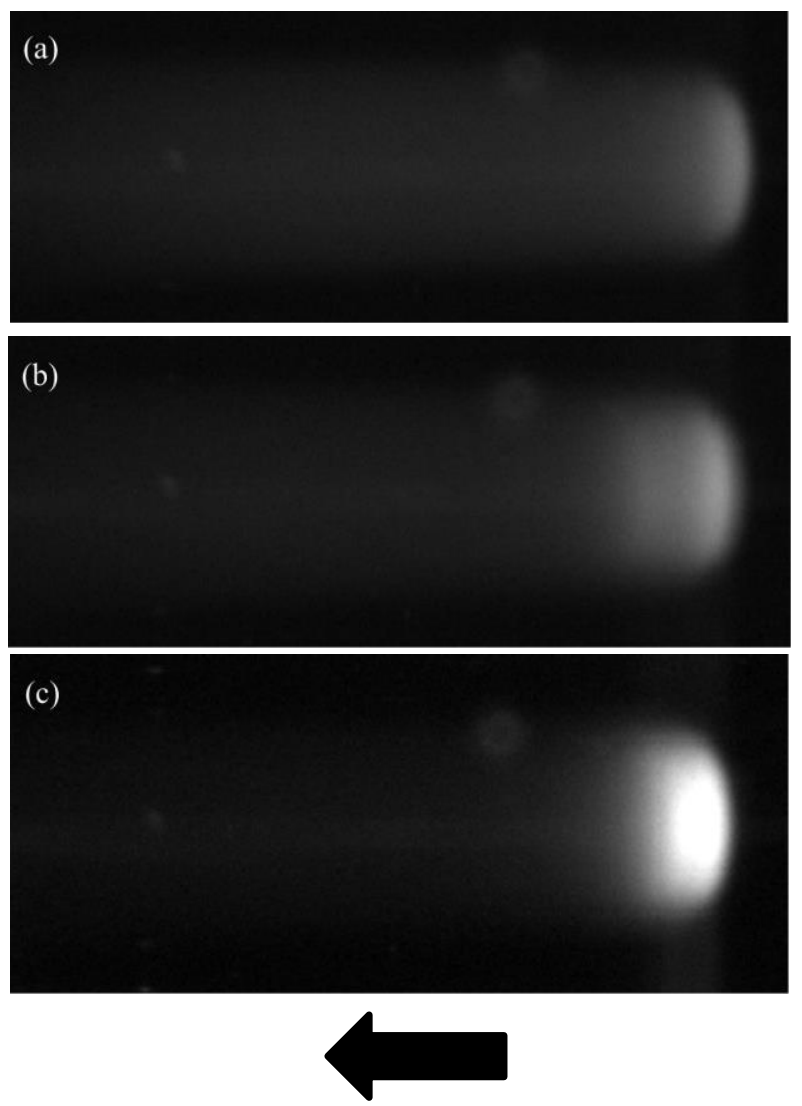

Flow

Fig. 4. Images of instable flames for a stoichiometric $\mathrm{CH}_{4} /$ air mixture and $2.15 \mathrm{~mm}$ inner diameter tube: the ignition occurs close to the blowtorches position (at left) while extinction is upstream. Flow rates: (a) $0.32 \mathrm{~m} / \mathrm{s}$, (b) $0.33 \mathrm{~m} / \mathrm{s}$, (c) $0.34 \mathrm{~m} / \mathrm{s}$. 
Temporal evolution of the $\mathrm{CH}^{*}$ signal is displayed on Fig. 5. One can notice on the Fig.5a the cyclic trace of the signal before the extinction. For example, at fresh gases velocity of 0.34 $\mathrm{m} / \mathrm{s}$ the number of oscillations is variable, whereas at $0.33 \mathrm{~m} / \mathrm{s}$, two oscillations before extinction are observed. At $0.32 \mathrm{~m} / \mathrm{s}$, the FREI regime without oscillation is observed as shown in Fig. 5b. The FREI regime occurs for fresh gases velocities down to $0.05 \mathrm{~m} / \mathrm{s}$. One can notice that the flame luminosity is increased artificially because the flame is oscillating at the same position.
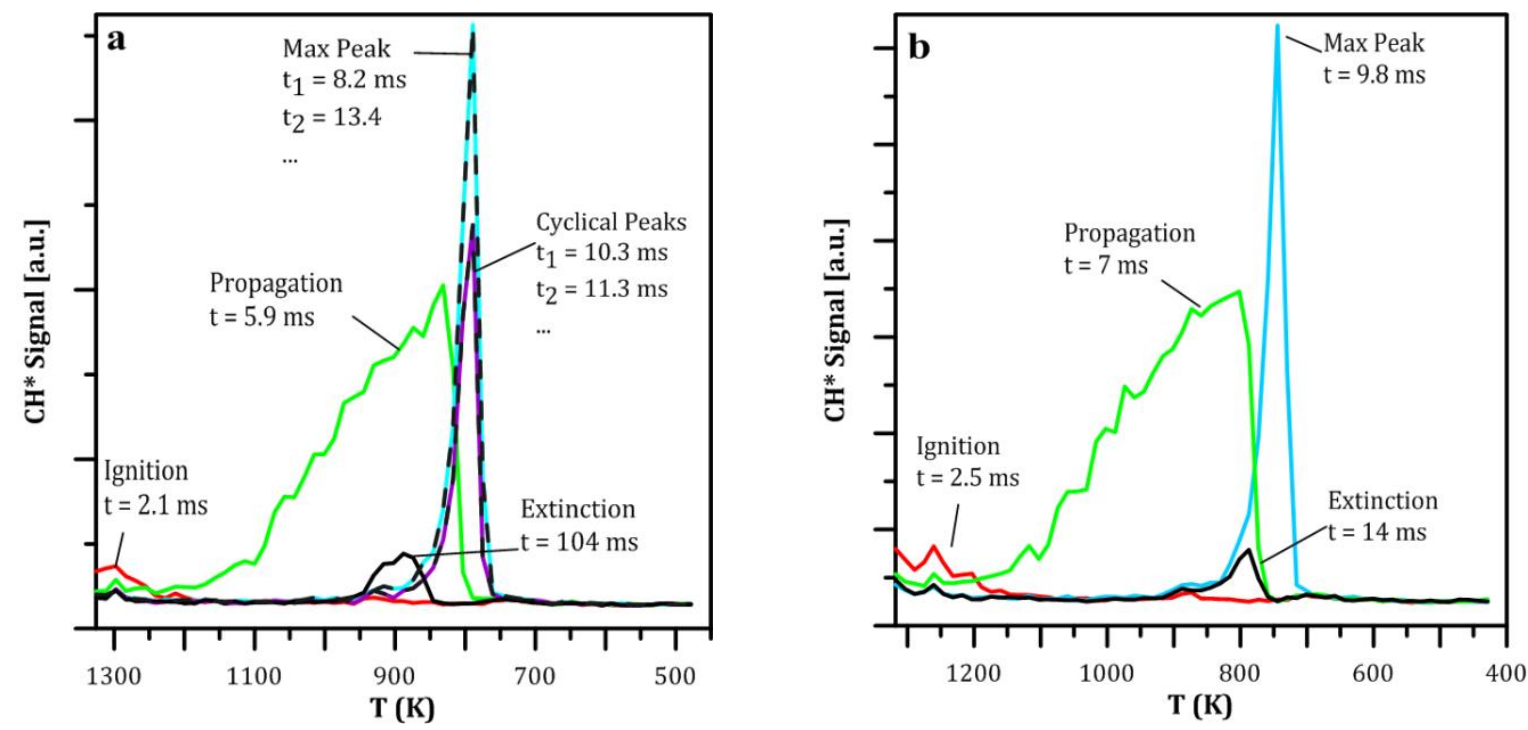

Fig. 5. Temporal evolution of FREI at (a) $0.34 \mathrm{~m} / \mathrm{s}$ and (b) $0.32 \mathrm{~m} / \mathrm{s}$. At $\mathrm{v}=0.34 \mathrm{~m} / \mathrm{s}$ the flame oscillates over several cycles before extinction.

Finally, weak flames, typical of mild combustion [24], are observed for velocities lower than $0.05 \mathrm{~m} / \mathrm{s}$. These weak flames have very low luminosity and, as shown in previous studies, the behavior of reactive mixture can completely change $[25,26]$ resulting in a weak temperature increase during the combustion process. At $0.04 \mathrm{~m} / \mathrm{s}$ oscillating weak flames are visible; this regime has been predicted numerically by Jackson et al. [23] and referred in [21] as a 'combination' flame with small amplitude. The weak flame becomes stable at $0.03 \mathrm{~m} / \mathrm{s}$, as shown in Fig. 6 b.
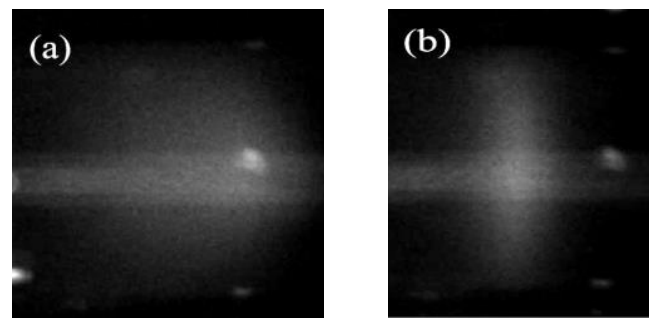

Fig. 6. Images of weak flames for a stoichiometric $\mathrm{CH}_{4} /$ air mixture in a $2.15 \mathrm{~mm}$ inner diameter tube: (a) at $0.04 \mathrm{~m} / \mathrm{s}$ where the flame oscillates, (b) at $0.03 \mathrm{~m} / \mathrm{s}$ where the flame is stable.

\subsection{Effect of flow velocity}

Figure 7 compares the results obtained here for a stoichiometric $\mathrm{CH}_{4} /$ air mixture and those obtained by Tsuboi et al. [21]: 


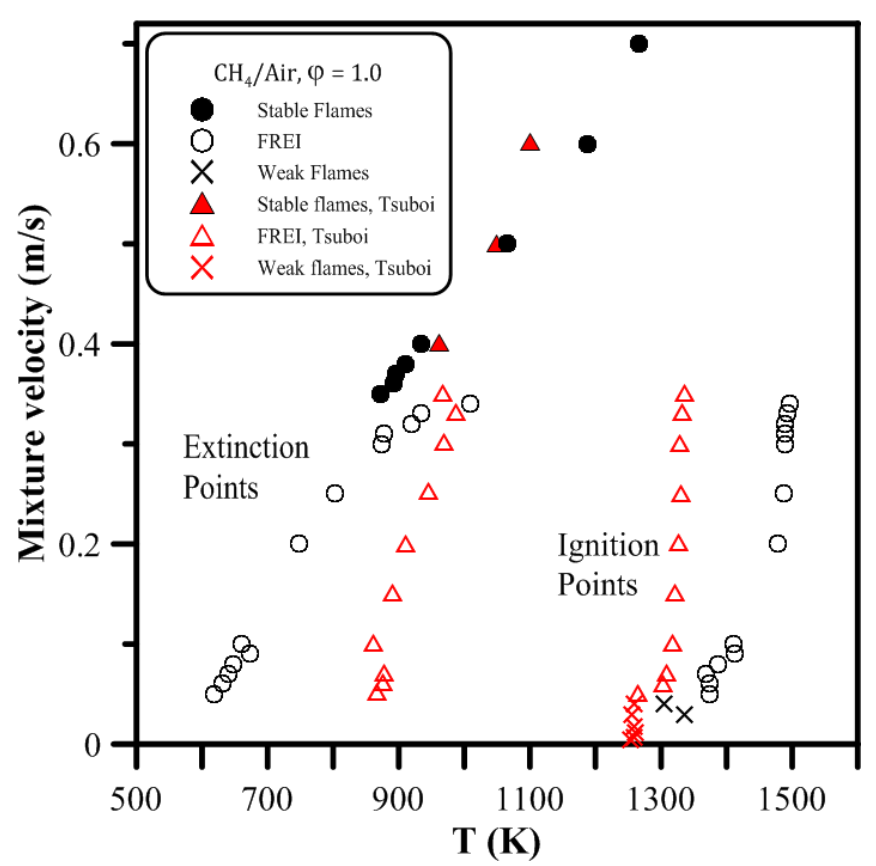

Fig. 7. Flame position as a function of wall temperature and mixture velocity.

The different flame behaviors described above are shown in Fig. 7. The solid symbols correspond to the stable flame case. The open symbols indicate FREI regime. Ignition occurs at high temperatures (right hand side) and extinction occurs at lower temperatures (left hand side). Weak flames are represented by crosses. The transition region between the stable flames and the FREI is clearly shown in this figure, with a discontinuity in the evolution corresponding to the "oscillating FREI" (0.32 - $0.34 \mathrm{~m} / \mathrm{s})$.

If we compare our results with those obtained by Tsuboi et al. [21, 27] one can see that the same trends are observed, but significant differences appear in terms of temperature readings. We believe that these differences are mainly due to differences in experimental setup. Primarily, the temperature gradient of the present study is steeper and micro blowtorches distribute heat evenly around the tube whereas in the experiments of Tsuboi et al. [21], the tube is heated from the below by a flat flame burner. Furthermore, the flame in the tube has an impact on the wall temperature. The temperature profile is measured continuously by the infrared camera in our experiments showing that heat released by the flame inside the tube cannot be neglected, as can be seen in Fig. 8 .

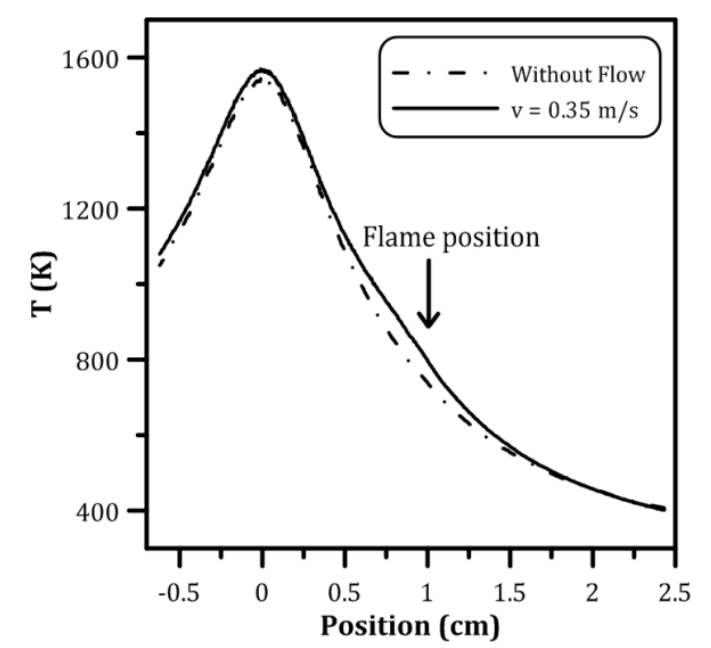

Fig. 8. Flame effect on the wall temperature profiles recorded (a) in absence of flow and (b) with flow of $0.35 \mathrm{~m} / \mathrm{s}$. 
To better understand the differences between the present results and those of Tsuboi et al. [21], experiments with two heat sources were carried out. The top burner was removed to simulate the heating from below used by Tsuboi et al. [21]. The results are shown in Fig. 9. It can be noticed that the shape of the flame is affected by the non-symmetric distribution of heat sources. With two heating sources, the flames brightness is less intense and they are angled, which brings uncertainty in the detection of the flame position and consequently uncertainty in the determination of temperature at the flame position.

Let us examine the trends in Fig 7, according to the different regimes observed. Firstly in the stable regime, the evolution of the stabilization temperature is quasi-linear for the high velocity regime of 0.6 to $1 \mathrm{~m} / \mathrm{s}$ (not shown in Fig 7). This area corresponds to the convex shape of the flame front. Then the dependency on flow velocity is emphasized, stabilization temperature is reduced with the speed reduction $(0.6$ to $0.35 \mathrm{~m} / \mathrm{s})$. This is the region where the flame front becomes concave (directed from the burned toward the unburned gas, Fig. 3). That makes it less sensitive to heat loss, as demonstrated by Daou and Matalon [20].

In the FREI regime, the dependence of the ignition and extinction points according to the inlet velocity is examined in more details. A weak dependency is observed for the ignition data points, except for very low velocity regimes where the ignition occurs at lower temperatures. The experimental data points obtained by Tsuboi et al. [21] are also very close to ours at low speed. Regarding extinction, a net temperature dependence of quenching is observed according to the flow velocity. Lower the inlet velocity is, lower the extinction temperature is. This phenomenon has been numerically investigated by Norton and Vlachos [28] and Minaev et al. [22]. From a phenomenological point of view the following explanation can be proposed: in the case of flames at moderate inlet velocity $(0.2$ to $0.34 \mathrm{~m} / \mathrm{s})$ the residence time is low, the convective time scale becomes short compared to the axial conductive time scale. This has a twofold effect. First, the flame loses little heat to the wall and more power is generated, resulting in a high temperature, and a short intense reaction zone. This is evidenced by the time tracking of $\mathrm{CH}^{*}$ signal which increases dramatically to form a narrow peak (see Fig. 5). Secondly, by reducing of heat transfer to the wall, it takes a longer distance to preheat the reacting mixture which will lead to the extinction of the flame by thermal quenching.

For low inlet velocities ( 0.05 to $0.2 \mathrm{~m} / \mathrm{s})$, the residence time is higher, the convective time scale becomes long. For slow flows, axial conduction through the gas and the solid dominates, spreading the heat, leading to nearly isothermal conditions. The wall temperature remains high while the power generated by the reaction decreases, resulting in an increase in heat lost relative to heat generated, causing extinction.

But, as shown in [29] for relatively weak flames the radicals recombination is exothermic and its released heat can stabilize the flame. At the same time the quenching properties change with materials [30]: the fused silica has a very good chemical inertness but its thermal conductivity depends on temperature [31]. As seen in reference [32], significant temperature gradients appear along the tube radius when the heat transfer coefficient increases, resulting in lack of flame propagation: by decreasing the tube diameter, gradients become weaker and the interaction between the gas and the wall is faster, leading to the increase of radical depletion effect. Furthermore, radical quenching is promoted with insulating materials, which do not strongly adsorb radicals: this could explain why at lower inlet velocity the flame extinguishes at lower temperature.

Regarding the most pronounced differences with the results of Tsuboi et al. [21] concerning the FREI extinction temperatures, the gap can be assigned to the non-uniformity of the wall temperature, the difference between top and bottom, causing an earlier thermal quenching. 

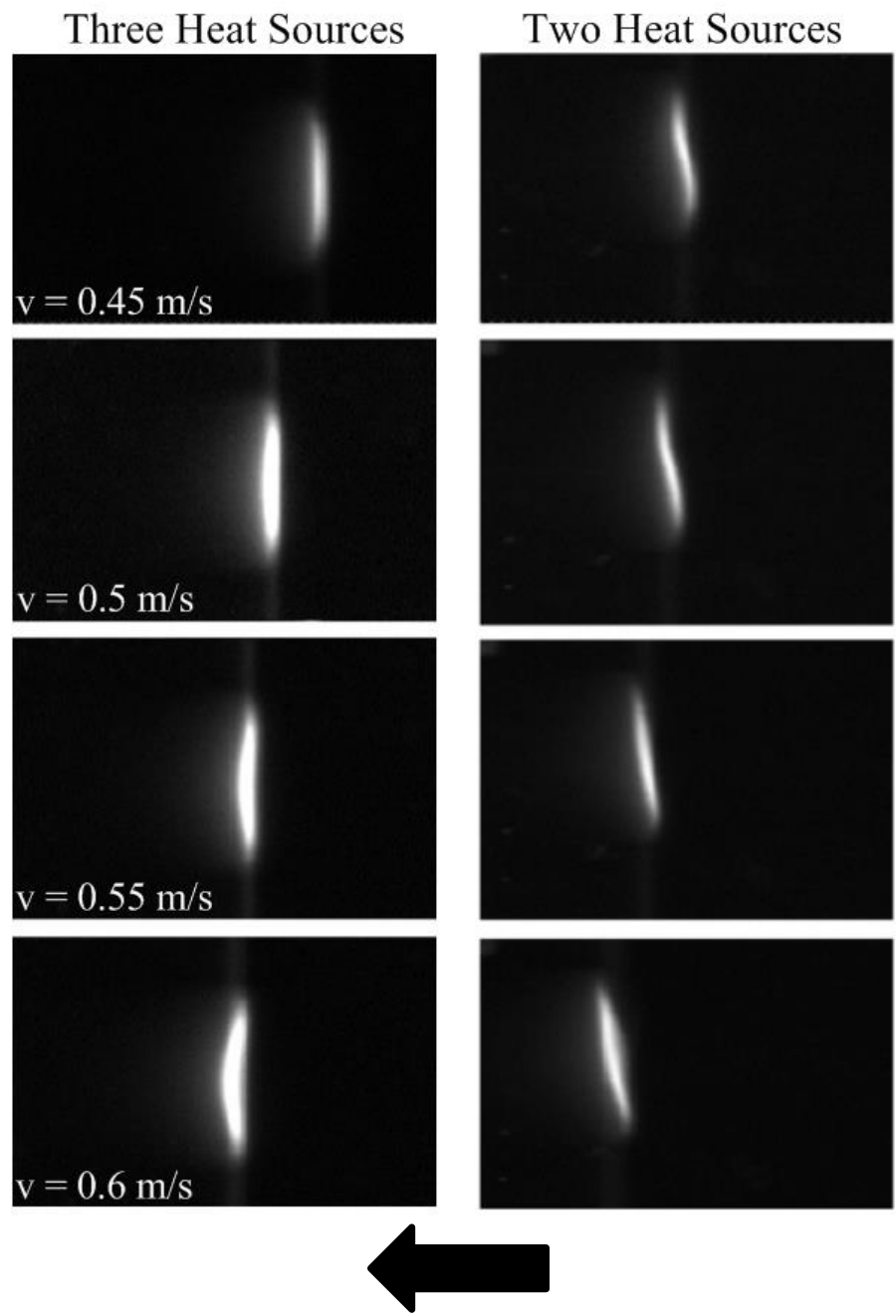

Flow

Fig. 9. Flames obtained with three and two heat sources at different flow velocities in a $2.15 \mathrm{~mm}$ diameter tube.

\subsection{Equivalence ratio effect}

Experiments were conducted over a range of equivalence ratios from 0.5 to 1.5 in a tube of $1.85 \mathrm{~mm}$ of internal diameter. The results are shown in Fig. 10. One can notice that for an equivalence ratio of 1.1, we have the lowest temperatures of stabilization (i.e. stable regime) and extinction (FREI regime). The flames obtained with a different equivalence ratio, lean or rich, stabilize at a higher temperature for stable regime, and for FREI regime, extinction temperatures follow the same trend.

This is due to the flame temperature [33] and the flame speed [19] which are higher near the stoichiometric condition. The higher temperature increases the heat transfer towards the wall and the convective exchange to fresh gas. However, as the flame velocity is itself increased, convective exchanges are favored over conduction. This allows the flame to stabilize at a lower wall temperature.

It can be noticed that the transition between stable and FREI regimes is different for the lean and the rich side (Fig. 10). For lean mixtures, this transition is effective for lower speeds when equivalence ratio decreases: $0.4 \mathrm{~m} / \mathrm{s}$ for $\varphi=1.1$ while it is $0.3 \mathrm{~m} / \mathrm{s}$ for $\varphi=0.5$. Conversely, the stable to FREI transition speed is slightly higher for rich mixture, and equal to 0.44 for $\varphi=1.5$.

For $\varphi<1$, FREI ignition points are omitted because the flames were less bright and ignition was difficult to precisely localize. 


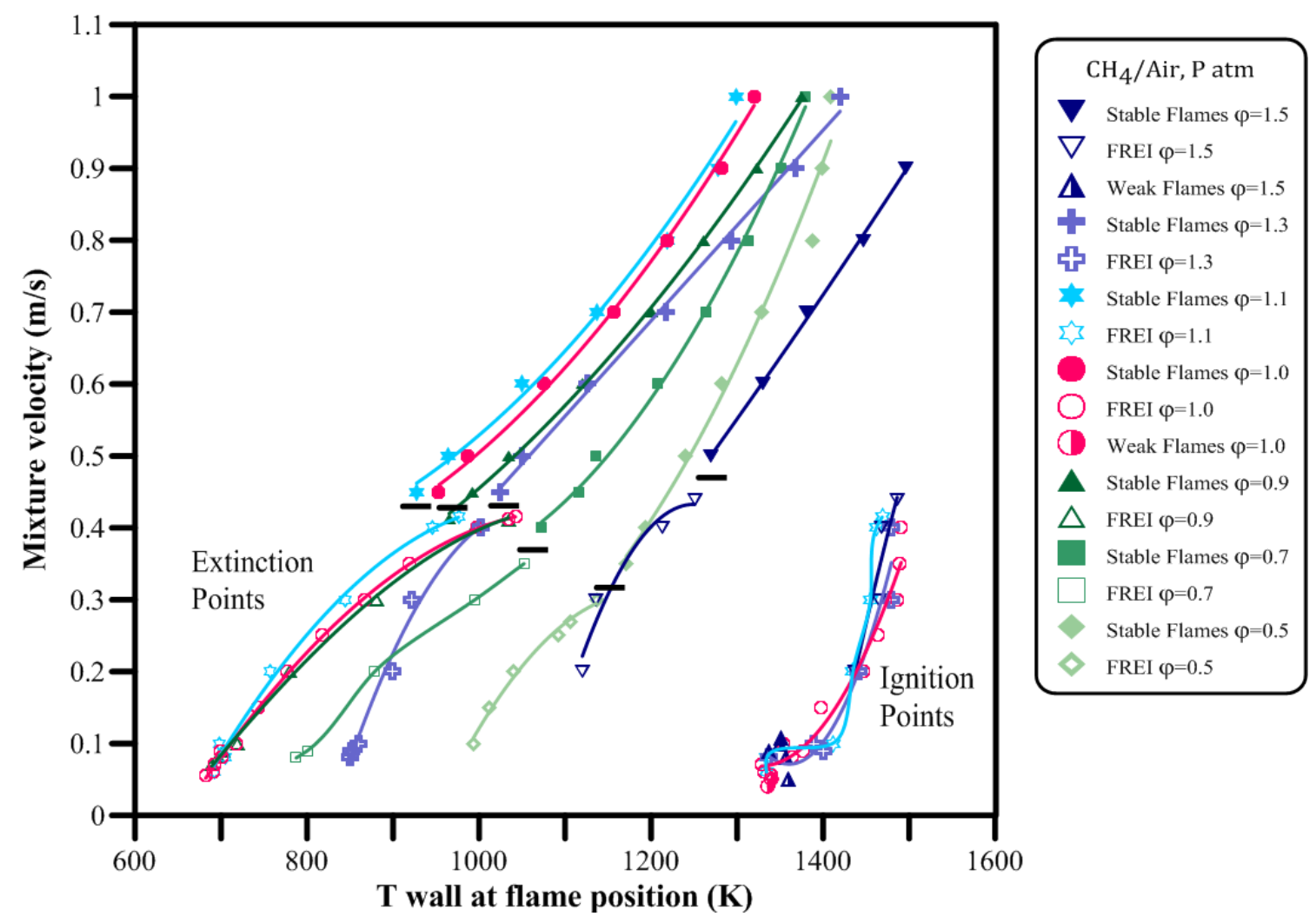

Fig. 10. The effect of equivalence ratio on flame positions.

\subsection{FREI frequencies}

The FREI regime is a specific regime where the flame ignites, spread on and extinguishes repeatedly with remarkable regularity over time. This feature allows us to perform a frequency analysis of the measured $\mathrm{CH}^{*}$ signal. Using a Fourier Transform analysis of the spectral cross-section of the $\mathrm{CH}^{*}$ signal (Fig. 11), the characteristic frequency of flames in FREI regime was determined. This characteristic frequency was determined for each flow rate and for each equivalence ratio considered here. Fig. 12 summarizes the results. The first point concerns the linear evolution of the frequency versus the flow velocity. The second concerns the minimization of the frequency for an equivalence ratio near stoichiometry, while the frequency increases as the equivalence ratio deviates from this optimum, either to the rich or to the lean side.

To explain the variation of frequency as a function of inlet velocity, we determined the characteristic time between ignition and extinction. The time between ignition and extinction of the flame $\left(\tau_{\mathrm{IE}}\right)$ and the time between the extinction and ignition $\left(\tau_{\mathrm{EI}}\right)$ are shown in Fig. 11.

The evolutions of these characteristic times depend on the velocity as shown in Fig. 13 for a fixed equivalence ratio. It can be noted that the time required to transport the fresh gas to the ignition point decreases with increasing flow rate, while $\tau_{\mathrm{IE}}$ does not change significantly. The FREI frequency being the inverse of the sum of these two characteristic times, implies that frequency increases with the increase of the inlet velocity. 


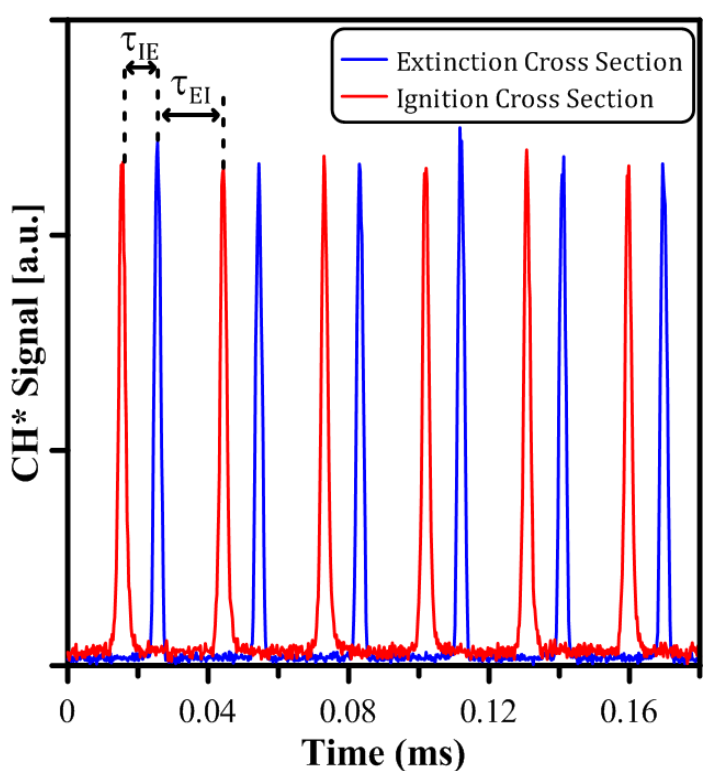

Fig. 11. Spectral cross-section $\mathrm{CH}^{*}$ signal.

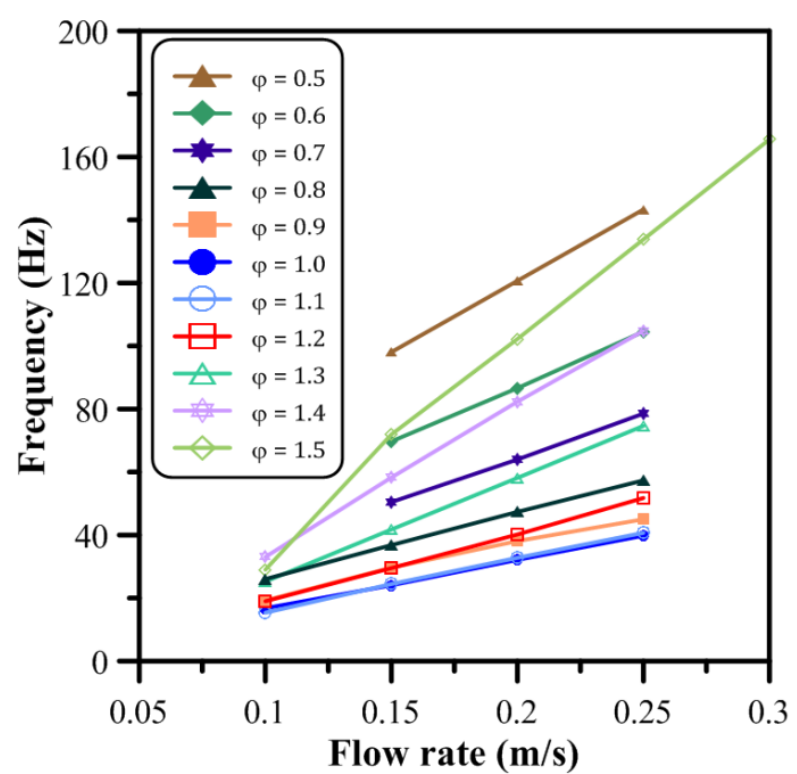

Fig. 12. FREI Frequency variation with inlet velocity, $\mathrm{d}=2.15 \mathrm{~mm}$

Similarly to Richecoeur et al.[34] who brought the Strouhal number to characterize the effect of diameter on the frequency, we have used the Strouhal number to characterize the effect of the equivalence ratio on the frequency. The Strouhal number is defined by $\mathrm{St}=\mathrm{f} \times \mathrm{d} / \mathrm{v}$, where $\mathrm{f}$ is the characteristic FREI frequency, $\mathrm{d}$ is the inner diameter of the tube and $\mathrm{v}$ is the inlet velocity. Figure 14 shows the evolution of the Strouhal number for different equivalent ratios. We observed a minimum of St near the stoichiometry $(1 \leq \varphi \leq 1.1)$ and equal to $\mathrm{St}=0.3$. It is interesting to note that this value is identical to that indicated by Richecoeur et al. [34] for curved channel, and by Crow and Champagne [35] as a preferred mode of vibration for incompressible jets.

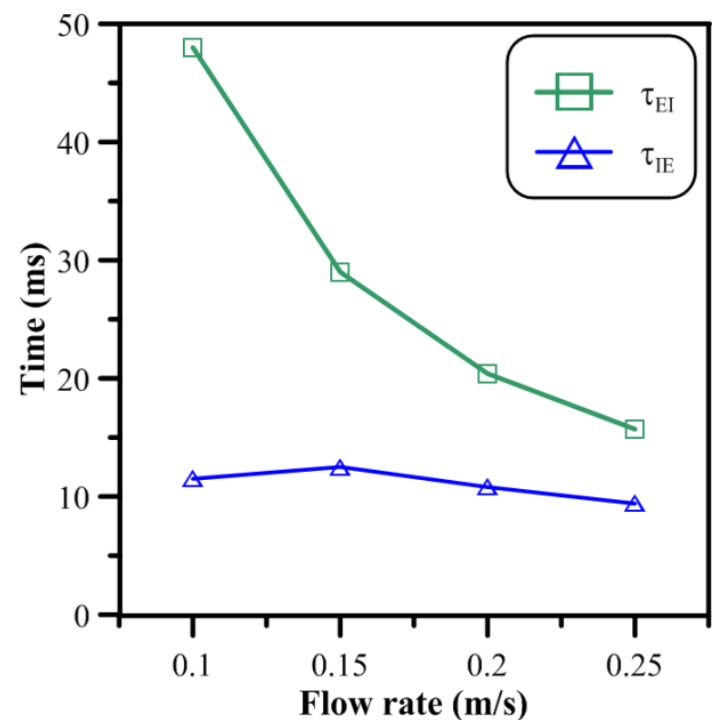

Fig. 13. Comparison between $\tau_{\mathrm{EI}}$ and $\tau_{\mathrm{IE}}$ for $2.15 \mathrm{~mm}$ diameter tube, $\varphi=1$

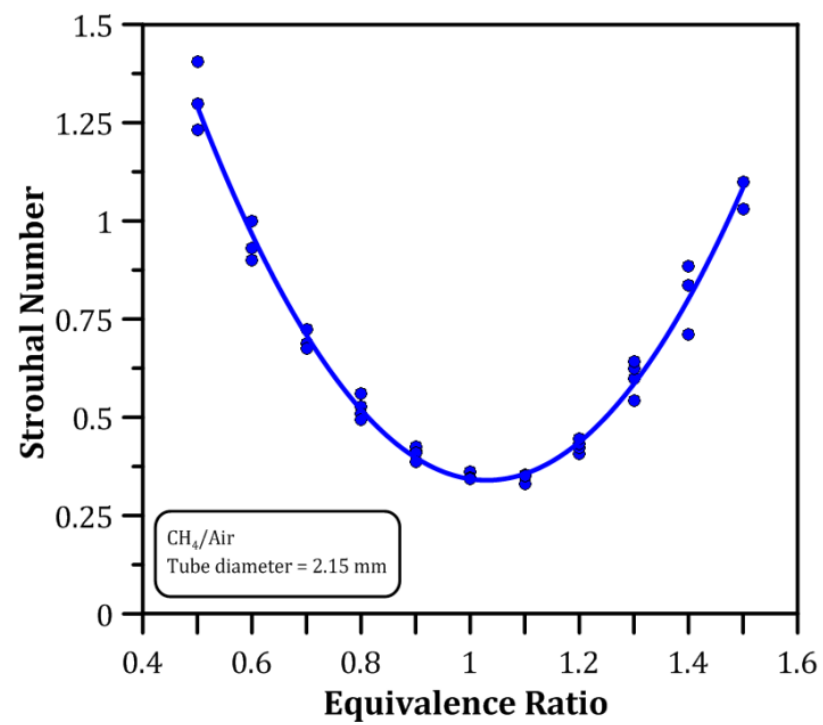

Fig. 14. Strouhal number at different equivalence ratios.

One can notice on Fig. 14 that the points are well superimposed to the minimum, while in rich and lean conditions there is a greater dispersion. One should note though that at very high frequency, there may be a greater experimental uncertainty. 


\section{Conclusions}

In this study, the combustion characteristics of $\mathrm{CH}_{4} /$ air mixtures in a micro channel were studied under various experimental conditions where we varied the inlet flow velocity and the equivalence ratio. The new experimental device is original by his heating method that ensures uniform radial temperature distribution, and by the diagnostics based on infrared thermography which allows a temporal tracking of the longitudinal temperature profile. The different regimes (stable, FREI, weak) observed in pioneering studies of Maruta et al. [17] were confirmed in this work. This work validates the reliability of the experimental setup. A systematic exploration of different equivalent ratios has allowed characterizing the dynamics of the flame according to this parameter. A detailed frequency analysis of the FREI regime has identified that the minimum frequency corresponds to a Strouhal number of 0.3 , and it correspond to a stoichiometric equivalent ratio.

\section{Acknowledgments}

The research leading to these results has received funding from the European Research Council under the European Community's Seventh Framework Programme (FP7/2007-2013) / ERC grant agreement $n^{\circ} 291049-2 \mathrm{G}-\mathrm{CS}$ afe.

$\begin{array}{ll} & \text { Nomenclature } \\ \mathrm{d} & \text { Tube diameter }(\mathrm{mm}) \\ \mathrm{v} & \text { Average fresh mixture velocity }(\mathrm{m} / \mathrm{s}) \\ \varphi & \text { Equivalence ratio (dimensionless) } \\ \mathrm{f} & \text { FREI frequency }(\mathrm{Hz}) \\ \mathrm{St} & \text { Strouhal number, } \mathrm{f} \mathrm{d} / \mathrm{v} \text { (dimensionless) } \\ \tau_{\mathrm{EI}} & \text { Time needed to heat up the fresh mixture }(\mathrm{ms}) \\ \tau_{\mathrm{IE}} & \text { Time required to blow out the flame }(\mathrm{ms})\end{array}$

\section{References}

[1] A.C. Fernandez-Pello, Micropower generation using combustion: Issues and approaches, Proc. Combust. Inst., 29 (2002) 883-899.

[2] D.C. Kyritsis, S. Roychoudhury, C.S. McEnally, L.D. Pfefferle, A. Gomez, Mesoscale combustion: a first step towards liquid fueled batteries, Exp. Thermal Fluid Sci., 28 (2004) 763-770.

[3] F.J. Weinberg, Combustion Temperatures: The Future?, Nature, 233 (1971) 239-241.

[4] S.A. Lloyd, F.J. Weinberg, A burner for mixtures of very low heat content, Nature, 251 (1974) 47-49.

[5] N.I. Kim, S. Kato, T. Kataoka, T. Yokomori, S. Maruyama, T. Fujimori, K. Maruta, Flame stabilization and emission of small Swiss-roll combustors as heaters, Combust. Flame, 141 (2005) 229-240.

[6] N.I. Kim, S. Aizumi, T. Yokomori, S. Kato, T. Fujimori, K. Maruta, Development and scale effects of small Swiss-roll combustors, Proc. Combust. Inst., 31 (2007) 3243-3250.

[7] M. Sánchez-Sanz, Premixed flame extinction in narrow channels with and without heat recirculation, Combust. Flame, 159 (2012) 3158-3167.

[8] J. Vican, B.F. Gajdeczko, F.L. Dryer, D.L. Milius, I.A. Aksay, R.A. Yetter, Development of a microreactor as a thermal source for microelectromechanical systems power generation, Proc. Combust. Inst., 29 (2002) 909-916.

[9] Y. Ju, K. Maruta, Microscale combustion: Technology development and fundamental research, Prog. Energy Combust. Sci., 37 (2011) 669-715.

[10] N.S. Kaisare, D.G. Vlachos, A review on microcombustion: Fundamentals, devices and applications, Prog. Energy Combust. Sci., 38 (2012) 321-359.

[11] F.N. Egolfopoulos, H. Zhang, Z. Zhang, Wall effects on the propagation and extinction of steady, strained, laminar premixed flames, Combust. Flame, 109 (1997) 237-252.

[12] J. Li, B. Zhong, Experimental investigation on heat loss and combustion in methane/oxygen micro-tube combustor, App. Thermal Eng., 28 (2008) 707-716.

[13] A. Veeraragavan, C.P. Cadou, Flame speed predictions in planar micro/mesoscale combustors with conjugate heat transfer, Combust. Flame, 158 (2011) 2178-2187. 
[14] P. Popp, M. Baum, Analysis of wall heat fluxes, reaction mechanisms, and unburnt hydrocarbons during the head-on quenching of a laminar methane flame, Combust. Flame, 108 (1997) 327-348.

[15] H. Bongers, L.P.H. De Goey, The effect of simplified transport modeling on the burning velocity of laminar premixed flames, Combust. Sci. Technol., 175 (2003) 1915-1928.

[16] A. Ern, V. Giovangigli, Thermal diffusion effects in hydrogen-air and methane-air flames, Combust. Theory Modelling, 2 (1998) 349-372.

[17] K. Maruta, T. Kataoka, N.I. Kim, S. Minaev, R. Fursenko, Characteristics of combustion in a narrow channel with a temperature gradient, Proc. Combust. Inst., 30 (2005) 2429-2436.

[18] R.M. Sova, M.J. Linevsky, M.E. Thomas, F.F. Mark, High-temperature infrared properties of sapphire, AlON, fused silica, yttria, and spinel, Infrared Physics \& Technology, 39 (1998) 251-261.

[19] C.Y.H. Chao, K.S. Hui, W. Kong, P. Cheng, J.H. Wang, Analytical and experimental study of premixed methane-air flame propagation in narrow channels, Int. J. Heat Mass Transfer, 50 (2007) 1302-1313.

[20] J. Daou, M. Matalon, Influence of conductive heat-losses on the propagation of premixed flames in channels, Combust. Flame, 128 (2002) 321-339.

[21] Y. Tsuboi, T. Yokomori, K. Maruta, Study on ignition and weak flame in heated meso-scale channel, in: ASME International Mechanical Engineering Congress and Exposition, Seattle, Washington, November 11-15, 2007, pp. 155-158.

[22] S. Minaev, K. Maruta, R. Fursenko, Nonlinear dynamics of flame in a narrow channel with a temperature gradient, Combust. Theory Modelling, 11 (2007) 187-203.

[23] T.L. Jackson, J. Buckmaster, Z. Lu, D.C. Kyritsis, L. Massa, Flames in narrow circular tubes, Proc. Combust. Inst., 31 (2007) 955-962.

[24] A. Cavaliere, M. de Joannon, Mild Combustion, Prog. Energy Combust. Sci., 30 (2004) 329-366.

[25] M. de Joannon, A. Cavaliere, T. Faravelli, E. Ranzi, P. Sabia, A. Tregrossi, Analysis of process parameters for steady operations in methane mild combustion technology, Proc. Combust. Inst., 30 (2005) 2605-2612.

[26] P. Sabia, M.d. Joannon, A. Picarelli, A. Chinnici, R. Ragucci, Modeling Negative Temperature Coefficient region in methane oxidation, Fuel, 91 (2012) 238-245.

[27] Y. Tsuboi, T. Yokomori, K. Maruta, Lower limit of weak flame in a heated channel, Proc. Combust. Inst., 32 (2009) 3075-3081.

[28] D.G. Norton, D.G. Vlachos, Combustion characteristics and flame stability at the microscale: a CFD study of premixed methane/air mixtures, Chem. Eng. Sci., 58 (2003) 4871-4882.

[29] P. Aghalayam, P.A. Bui, D.G. Vlachos, The role of radical wall quenching in flame stability and wall heat flux: hydrogen-air mixtures, Combust. Theory Modelling, 2 (1998) 515-530.

[30] C.M. Miesse, R.I. Masel, C.D. Jensen, M.A. Shannon, M. Short, Submillimeter-scale combustion, AIChE J., 50 (2004) 3206-3214.

[31] K.L. Wray, T.J. Connolly, Thermal Conductivity of Clear Fused Silica at High Temperatures, J. Appl. Phys., 30 (1959) 1702-1705.

[32] S. Raimondeau, D. Norton, D.G. Vlachos, R.I. Masel, Modeling of high-temperature microburners, Proc. Combust. Inst., 29 (2002) 901-907.

[33] A. El Bakali, P. Dagaut, L. Pillier, P. Desgroux, J.F. Pauwels, A. Rida, P. Meunier, Experimental and modeling study of the oxidation of natural gas in a premixed flame, shock tube, and jet-stirred reactor, Combust. Flame, 137 (2004) 109-128.

[34] F. Richecoeur, D.C. Kyritsis, Experimental study of flame stabilization in low Reynolds and Dean number flows in curved mesoscale ducts, Proc. Combust. Inst., 30 (2005) 2419-2427.

[35] S.C. Crow, F. Champagne, Orderly structure in jet turbulence, J. Fluid Mech., 48 (1971) 547-591. 